\title{
DESCIFRANDO MÍSTICA CIUDAD DE DIOS, OBRA DE SOR MARÍA DE JESÚS DE ÁGREDA
}

\author{
Violeta GiovanninI \\ UNED \\ magicpinkquartz@hotmail.com
}

\section{RESUMEN}

Se emprende el estudio de Mística Ciudad de Dios, de Sor María de Jesús de Ágreda, centrándolo desde una perspectiva estructural y de estilo. El principal objetivo es demostrar, desde un punto de vista filológico, la existencia de un rico vocabulario propio, una estructura interna basada en conceptos matemáticos, así como de figuras del "equívoco". Se concluye afirmando la intención didáctica, metafísica e histórica de esta obra del Siglo de Oro.

Palabras Clave: Siglo de Oro Barroco; Mística Ciudad de Dios; divina Historia; Sor María de Jesús de Ágreda; Felipe IV.

\section{AbStract}

A study of The Mystical City of God, Sister Mary of Jesus of Ágreda's book is carried out, from a structural perspective and literary style. The main objective is to demonstrate, from a philological point of view, the existence of a rich vocabulary, an internal structure based on mathematical concepts, as well as rhetorical devices. We conclude that this opus of the Golden Age was written with didactic intentions, and as a metaphysical and historical guide.

Key Words: Baroque Golden Century (Spanish Golden Age); The Mistycal City of God; divine History; Sister Mary of Jesus of Ágreda; Philip IV.

Una de las grandes desconocidas dentro de la literatura mística y religiosa del siglo XVII es la Venerable Sor María de Jesús de Ágreda. Su vida y su obra se desarrollan dentro de un periodo de la historia marcado por una fuerte crisis económica junto con el desmoronamiento 
paulatino del imperio español. A la par de estas desgracias, la propia dinastía de los Austrias marchaba hacia su disolución poniendo fin al reinado de la casa Habsburgo en España.

Probablemente tan desolador panorama histórico, ligado a la influencia que ejerció sobre el rey Felipe IV, pudo influir en la poca trascendencia de Sor María de Jesús en el ámbito literario. Sin embargo, en lo que a tratados místicos se refiere, la actividad creadora de la Venerable es importante. De ella son las obras siguientes:

Jardín espiritual para recreo del alma (1621): es uno de sus primeros trabajos, escrito en su juventud y copiado y sacado a escondidas del torno claustral por sus compañeras de congregación para complacer a quienes eran benefactores de su comunidad religiosa. Adopta la forma de diálogo entre el alma y los ángeles, a quienes pregunta sobre cuestiones piadosas.

Letanía en loor de la Virgen (1630): copiada y divulgada sin el consentimiento de Sor María, fue publicada en Madrid y Zaragoza poco tiempo después (1631).

Ejercicios espirituales (1645): enfocado básicamente hacia las hermanas que busquen hacer las penitencias con las oraciones y ejercicios propuestos por la autora.

Leyes de la esposa (1634-1655): esta obra está dividida en tres partes coincidentes con los diferentes períodos en que fueron redactadas: leyes primeras (1634-1637), segundas (1641-1642) y terceras (1655). Tiene una finalidad didáctica moralizante.

Algunos sucesos de doctrina y enseñanza para la alma (1660): breve opúsculo datado después de Mística Ciudad de Dios, en el que Sor María se propone dirigir su conciencia como si del último día de su vida se tratara. En él se acusa de diferentes faltas que considera necesario escribir como acto de humildad y se ofrecen las respuestas del Altísimo ante sus preguntas.

Las Sabatinas (1651-1655): apuntes escritos para la revisión de su confesor particular, eran entregados los sábados de cada semana para darle cuenta de todo cuanto le acontecía espiritualmente.

Tomo V, llamado así por ser el quinto volumen ${ }^{1}$ de la edición que se llevó a cabo en 1911 sobre Mística Ciudad de Dios.

Escala para subir a la perfección (1665): inacabada por la muerte de la autora, que advierte de los peligros de adentrarse en el sendero místico, es una obra que contiene profundos elementos psicológicos, y en cuya introducción Sor María de Jesús de Ágreda nos da las sutiles claves de la técnica que utiliza para poder conseguir sus arrobos místicos.

Mística Ciudad de Dios: su obra de madurez. Los periodos en que la compuso son dos, de 1637 a 1643, que fue el de la primera redacción, siendo destruida esta por el fuego en 1645; de 1655 a 1660, que fue el de la segunda, rehecha a petición de su confesor, el padre Andrés de Fuenmayor. Esta obra es el objetivo de nuestro estudio.

${ }^{1}$ Es autobiográfico hasta el capítulo III del tratado segundo de los diez que posee. Tras el fallecimiento de la Venerable se amplió la documentación con los datos de todos los que la conocieron más de cerca. Posee un extracto del interrogatorio inquisitorial realizado en 1650. 
El corpus literario de temática mística de Sor María carece de estudios filológicos profundos como los hay sobre obras de otros autores también con título de santos, bien por lo antes indicado, bien por los temas tratados por la propia autora, que de forma directa y explícita aborda cuestiones eclesiásticas y teologales bastante complejas. Incluso las referencias sobre ella en manuales históricos y literarios son mínimas y de ellas reseñaremos brevemente lo que hemos encontrado.

El hispanista inglés R. A. Stradling, al indagar en la Historia de España durante el reinado de Felipe IV, dentro de su amplio estudio escribe lo siguiente sobre la Venerable y su amistad con el monarca:

Inmune a consideraciones de carácter sexual o material, libre de la política de facciones implícita en el trato con los cortesanos y exenta, en definitiva, de todo tipo de formulismos relacionados con la posición social, la relación de Felipe IV con Sor María permitía —o más bien, exigía — una comunicación absolutamente franca, sencilla y completa. Era como pensar en voz alta, como recogerse en sí mismo o fundirse en su alter ego ${ }^{2}$.

Existen trabajos más exhaustivos apoyados en los testimonios epistolares ${ }^{3}$ que permiten una aproximación mayor tanto a la figura de Sor María como a las de aquellos con quienes se escribía ${ }^{4}$. Un ejemplo de ellos es la correspondencia con el duque de Híjar, el Virrey Fernando de Borja o Felipe IV $^{5}$. En estas epístolas se trataba de todo lo referente a cuestiones de Estado y se daban consejos espirituales. El elemento críptico es determinante ante los delicados temas mencionados en dichas cartas ${ }^{6}$.

En relación con la obra cumbre de Sor María de Jesús, Ángel del Río, en su Historia de la Literatura Española anota sobre Mística Ciudad de Dios:

Otro género que es también simple continuación del impulso recibido es el de la literatura religiosa, aunque aquí la decadencia es más evidente. Lo característico es que el misticismo sea llevado a sus consecuencias extremas, ya literarias, en las fantásticas visiones de La Mística Ciudad de Dios (1670), de sor María de Ágreda; $[\ldots]^{7}$.

${ }^{2}$ Stradling, R. A., Felipe IV y el gobierno de España, 1621-1665, Cambridge, Cátedra, 1988, p. 452.

${ }^{3}$ Seco Serrano, C., Estudio preliminar a la edición de las Cartas de Sor María de Ágreda y de Felipe IV: Epistolario español, Madrid, IV BAE, 1958; La Madre Ágreda y la política de Felipe IV, en Monografías Universitarias núm. 15: La Madre Ágreda una mujer del siglo XXI, Soria, Universidad Internacional Alfonso VIII, pp. 11-24.

${ }^{4}$ Pérez Villanueva, J. Felipe IV, escritor de cartas, Salamanca, Caja de Ahorros y Monte de Piedad, 1986. Este libro es un estudio sobre la correspondencia del rey con Sor Luisa, nombre de clausura de la Condesa de Paredes, y lo compara con aquellas otras cartas que el monarca intercambiaba con Sor María de Jesús de Ágreda. Sor María de Ágreda y Felipe IV: un epistolario en su tiempo, sin fecha o lugar.

5 Baranda Leturio, C. María de Jesús de Ágreda. Correspondencia con Felipe IV. Religión y razón de estado. Madrid, Castalia, 1990.

${ }^{6}$ Baranda Leturio, N., Cartas de Sor María Jesús de Ágreda a Fernando de Borja y Francisco de Borja (16281664), Universidad de Valladolid, 2013, pp. 32-37. Otros estudios: Baranda Leturio, N., y Marín Pina, C. Letras en las celdas, Cultura escrita de los conventos femeninos en la España moderna, Iberoamericana, Vervuerte, 2014.

7 Rio, A. del, Historia de la Literatura Española, desde los orígenes hasta 1700. Nueva York, Libro amigo ensayos, 1963, p. 652. 
Existen ediciones ${ }^{8}$ que abordan el estilo literario en Las Sabatinas, La Escala para subir a la perfección y Algunos sucesos de doctrina, así como trabajos que analizan de forma mariológica y teológica los conceptos que aparecen en Mística Ciudad de Dios ${ }^{9}$.

\section{DESENCRIPTANDO MÍSTICA CIUDAD DE DIOS}

Expondremos brevemente la forma en que hemos abordado el estudio de Mística Ciudad de $\operatorname{Dios}^{10}$, partiendo de la consideración de las palabras de la autora, que afirma:

En este conocimiento hay modos y grados de ver [...] (MCD, 24).

Tres son los propósitos de este trabajo. El primero de ellos, que surge ante una primera lectura de Mística Ciudad de Dios, es intentar, en la medida de lo posible, desencriptar el código que utiliza Sor María de Jesús para transmitirnos diferentes mensajes. El segundo propósito, una vez vistos los elementos o variables que utiliza en el tratamiento del lenguaje, es agrupar mediante la asociación todos aquellos temas (históricos, psicológicos, científicos, médicos y mistéricos) que la propia Sor María destaca para poder dar un significado o contenido uniforme a dichos mensajes. Por último, demostrar que no se trata de un compendio exclusivamente moralizante, sino que es una obra que sintetiza el saber de una época.

Damos por sentado que está escrito por Sor María de Jesús de Ágreda, sin ningún tipo de duda sobre ello. En la obra es característico el uso, tanto del lenguaje como del vocabulario, de forma ajena a lo normativo. Es definido y acotado, incluso en la propia norma ortográfica que Sor María propone, dando a su composición connotaciones de significado que la hacen única. Ella crea un mundo propio cuyo estudio literario hemos enfocado ciñéndonos a la estructura, el estilo y el contenido mismo de la obra:

Y asegúralo más diciendo: Yo soy alfa y omega, la primera y última letra, que como principio y fin encierro la perfección de todas las obras, porque si les doy principio es para llevarlas hasta la perfección de su último fin. (MCD, 118).

Partimos del concepto de que esta obra literaria es un elemento de comunicación en sí misma:

Vio que tan suma bondad era convenientísima en su equidad y, como debido y forzoso, comunicarse, para obrar según su inclinación comunicativa [...] (MCD, 32).

${ }^{8}$ Sor María de Jesús de Ágreda: Las Sabatinas, Peña García, M. (ed.), Soria 2005.

- Escala para subir a la perfección, Peña García, M. (ed.), Soria 2012.

- Algunos sucesos de doctrina y enseñanza para la alma, Fuente Fernández, F. J. (ed.), León, 1993.

${ }_{9}^{9}$ Martínez Moñux, A., María, mística ciudad de Dios, una mariología interactiva, Soria, Monte Carmelo, 2001. Este es un gran trabajo que recopila y clasifica toda la bibliografía disponible sobre la historia de la teología del s. XVII, obras mariológicas anteriores y posteriores a este siglo, los estudios de orden mariológico en relación con Mística Ciudad de Dios, personalidad de la autora y el entorno cultural de su época.

${ }^{10}$ Sor María de Jesús de Ágreda, Mística Ciudad de Dios, [1965], Madrid, Solaguren, C. (ed.), 2009. Cuarta reimpresión de la edición de 1965, con la que estamos trabajando, que conmemoraba el tercer centenario de la muerte de Sor María. Hicieron una edición crítica con la única licencia de transcribir con ortografía moderna el texto para una lectura más asequible. Las variaciones vienen explicadas en el prólogo de la Introducción. 


\subsection{Desarrollo sucinto del esquema de comunicación}

1. El emisor es nuestra autora, Sor María de Jesús de Ágreda, abadesa del convento de Ágreda, perteneciente a la orden concepcionista franciscana fundada en el siglo XVI por la madre Beatriz da Silva ${ }^{11}$.

2. El receptor es, en primer lugar, según hemos deducido, el rey Felipe IV, quien recibió de la autora la primera copia del primer manuscrito, terminado en 1643 y entregado al monarca cuando se dirigía a Zaragoza para hacerse cargo del ejército apostado entre Aragón y Cataluña ${ }^{12}$. En segundo lugar, son receptoras las hermanas del convento, que guardan el manuscrito original de la segunda redacción. Finalmente, son receptores todos aquellos que lo lean, o como Sor María dice:

Quien llegare a entender -si por dicha entendiere alguno [...] (MCD, 3).

3. El "código" es utilizado desde un punto de vista críptico, conceptista y alegórico, con profusión de metáforas cuya correspondencia entre lo real y lo alegórico les era familiar a determinados lectores cultos, que podían perfectamente entender el mensaje de la obra. De esta forma el contenido, completamente encriptado, ofrece varios niveles de lectura.

4. El "ruido" son las elucubraciones filosóficas y/o teológicas en relación con lo escrito, que de algún modo sirven a Sor María de "caparazón” para esconder lo que realmente hay debajo. Podemos incluir las censuras y estudios que sufrió el libro por parte de la Inquisición ${ }^{13}$ y es inevitable añadir la misoginia, no sólo de la sociedad de su época, sino de aquellos historiadores que no entienden que una mujer, monja de clausura, pudiera dar consejos espirituales o de estado al rey de una nación en crisis.

5. En el ámbito metalingüístico hay que resaltar el aspecto lúdico que invadía la vida cotidiana de la clase culta ${ }^{14}$, por lo que el carácter sumamente severo que se pretende dar a la obra se diluye en el contexto social elitista de la época. En algunos momentos de la obra el "juego" aparece de forma evidente y es uno de los pilares de apoyo a la hora de desentrañar muchos de los mensajes transmitidos. Así, los supuestos "errores" doctrinales de los que se acusa a Sor María, dejan de serlo porque significan conceptos completamente diferentes de lo que aparentan.

6. Como mensaje del tratado, Sor María dijo:

11 Canonizada en 1950.

${ }^{12}$ Stradling, R. A., Felipe IV y el gobierno de España (1621-1665), Cambridge, Cátedra, 1988.“[...] el viaje a Aragón [...] permitió que los franceses se apoderaron de una fortaleza especialmente valiosa desde el punto de vista estratégico, la de Lérida, que tan cerca estaba de la propia Zaragoza." (p. 309). Pero tras la batalla en 1643, "Lérida había capitulado y vuelto a jurar lealtad a España." (p. 317).

${ }^{13}$ Martínez Moñux, A., María, mística ciudad de Dios, una mariología interactiva, Soria, Monte Carmelo, 2001, p. 44: afirma este autor que desde su edición en 1670 "el examen duró 16 años".

${ }^{14}$ Huizinga, J., Homo ludens, Madrid, Alianza, 1987. Hacemos referencia a la totalidad de esta obra para comprender lo que es el sentimiento lúdico, el concepto juego, la intención lúdica y, finalmente, la figura del "aguafiestas". 
[...] fundó el Altísimo esta ciudad de María, franqueó liberalmente sus tesoros y por ella quiso llamar a todos los mortales al conocimiento de sí mismo y a la eterna felicidad sin excepción de gentiles, judíos, ni bárbaros, sin diferencia de naciones y de estados, por eso edificó esta ciudad santa con doce puertas a todas las cuatro partes del mundo sin diferencia. [...] (MCD, 1137).

La doctrina que nos muestra Sor María es la siguiente:

[...] todos entiendan que María santísima tiene escritos sus nombres en el pecho y en los mismos favores que recibió del Altísimo para ser Madre de clemencia y misericordia y no de la justicia. [...] (MCD, 1137).

El mensaje de la doctrina de la Madre divina está frente a la del Padre eterno. Frente al castigo de la justicia se enfatiza más la clemencia o compasión.

\section{PILARES DE LA DESCODIFICACIÓN}

\section{Básicamente son tres:}

1. El concepto tiempo: concebido de forma circular, en vez de lineal, es tratado de diversos modos. Al principio del libro, "tiempo"15 es un personaje que Sor María desarrolla junto con otros conceptos como "luz" o "verbo". Posteriormente, se transforma en un elemento de cohesión de la acción mediante cómputos temporales que calcula la propia autora para hacer ver al lector que las fechas coinciden, y la acción tiene una coherencia temporal. Por último, lo que resulta tremendamente original, es la utilización del tiempo como "codo temporal" para narrar dos o más acciones simultáneas, una evidente y otra, u otras, que se sobreentienden.

2. Los motivos argumentales: un pequeño ejemplo es la forma o motivos que utiliza Sor María al referirse hacia su obra. Mediante el primer motivo o "Historia", nos da a entender el argumento como una explicación de la vida de la que Sor María forma parte y la ilustración velada de las circunstancias de todas aquellas personalidades históricas con las que trató. El segundo motivo, o "divina Historia", hace referencia a otra obra, La Divina Comedia de Dante Alighieri; en los primeros capítulos de Mística Ciudad de Dios Sor María desarrolla y expone su personalísimo punto de vista sobre los conceptos que aparecen en los cantos 32 y 33. Otros muchos más motivos van apareciendo en un momento dado y posteriormente se desarrollan con mayor intensidad, generando una polifonía argumental profundamente barroca.

3. El concepto juego, antes mencionado, es esencial para entender que la obra en sí tiene sus propias reglas, creando un mundo aparte con una norma ajena. No es en vano que la autora constantemente afirme de una u otra forma:

Sígueme y trabaja por imitarme, pues hallaste el tesoro escondido y la margarita preciosa, por cuya posesión debes privarte de todo lo terreno y de tu misma voluntad, en cuanto fuere contraria a la del altísimo Señor y mío (MCD, 863).

\footnotetext{
15 Concebido en ‘instantes’ y utilizado para la interpretación del Génesis, en el Libro I de MCD.
} 
Para entender el mensaje el lector debe hallar ese "tesoro" al margen del mundo exterior o terrenal. Con el "organigrama" propio que el mismo libro nos muestra, utilizamos la asociación de conceptos. La aparición en un determinado contexto, y la posterior repetición de esos mismos términos, nos llevan a agrupar significados con un mensaje muy específico. Lo lúdico o "divertido" consiste en relacionar todo y saber qué nos narra Mística Ciudad de Dios.

\section{VIDA DE MARÍA}

Como muestra de nuestra aportación al estudio de la obra vamos a exponer este ejemplo para aplicar lo señalado en los apartados anteriores.

A lo largo de la "divina historia", a través de la vida de María santísima, o madre de Jesús, Sor María nos transmite todos los detalles de su propia vida personal para que podamos conocerla y entender que Mística Ciudad de Dios también es un libro autobiográfico.

Entre los conceptos más importantes que encontramos, está el de "asimilación-imitación". Esta noción aristotélica se basa en que el buscador de la Verdad no sólo se identifica con la Bondad o las más bellas cualidades, sino que se hace uno con ellas: no hay diferencia entre el objeto de imitación y el que quiere imitarlo. La fusión es total, invade toda la conciencia del individuo.

Hija mía y esposa mía, tu amor y fidelidad sobre todas las criaturas nos obliga y nos da la plenitud de complacencia que nuestra voluntad santa desea. Asciende a nuestro lugar y trono, para que seas absorta en el abismo de nuestra divinidad y tengas en esta Trinidad el lugar cuarto, en cuanto es posible a pura criatura. Toma la posesión de nuestra gloria, cuyos tesoros ponemos en tus manos. Tuyo es el cielo, la tierra y todos los abismos. Goza en la vida mortal los privilegios de bienaventurada sobre todos los santos. Sírvanse todas las naciones y criaturas a quien dimos el ser que tienen, obedézcante las potestades de los cielos y estén a tu obediencia los supremos serafines, y todos nuestros bienes te sean comunes en nuestro eterno consistorio. Entiende el gran consejo de nuestra sabiduría y voluntad y ten parte en nuestros decretos, pues tu voluntad es rectísima y fidelísima. Penetra las razones que tenemos para lo que justa y santamente determinamos, y sea un tu voluntad y la nuestra y uno el motivo en lo que disponemos para nuestra Iglesia (MCD, 1280).

El concepto de "María santísima" invade todos los rincones de la conciencia de Sor María de Jesús. Ese estado ideal lo denomina "María Milagro"16, refiriéndose a sí misma como resultado de un proceso místico.

\subsection{Autoría}

Como escritora Sor María de Jesús es una emisora omnisciente y omnipresente desde el principio hasta el final de la obra. Pero a partir del capítulo 19 del Libro I se transforma

16 Término que la propia autora introdujo en el título en la segunda redacción, cambiándolo de la primera que decía "Mística Ciudad / de Dios Milagro de su omni / potencia [...]" por "Mística Ciudad de Dios/Vida de María milagro de su omnipotencia/ y abismo de la Gracia [...]". Este cambio lo pidió su confesor. 
también en receptora de una doctrina."María santísima" es la "Maestra" o emisora real, y la autora se transforma en simple mensajera de lo que le está dictando su divina Maestra. Esto ocurre en la sección que la autora denomina "doctrina".

Toda esta práctica de humildad creadora proporciona la causa para autodenominarse "vil gusanillo", aunque no deja de ser una actitud de prudencia porque, salvo por el título inicial de la segunda copia que escribió y que se conserva, a lo largo de toda la obra no se sabe su autoría, si bien al final, como firma, enlazándolo con la ciudad de Zaragoza y uniéndolo a la figura de la Virgen del Pilar, sí que nos revela su nombre de religiosa de la siguiente forma ${ }^{17}$ :

[...] Y llamar a la Reina Madre de Dios fue acuerdo de los apóstoles después que ordenaron el Credo, y que unos con otros la llamasen Virgen y Madre, por lo que importaba a la santa Iglesia asentar en el corazón de todos los fieles el artículo de la virginidad y maternidad de esta gran Señora. Algunos otros fieles la llamaban María de Jesús o María la de Jesús Nazareno; otros menos capaces la nombraban María, hija de Joaquín y Ana; y de todos estos nombres usaban los primeros hijos de la fe, para hablar de nuestra Reina. Pero la santa Iglesia, usando más del que le dieron los apóstoles, la llama Virgen y Madre de Dios, y a éste ha juntado otros muy ilustres y misteriosos. [...] (MCD, 1340).

Vemos que se escuda en el concepto de "madre", que junto al nombre de hermana, o sor, es el modo de denominar a las monjas. En este pasaje, los "apóstoles" serían aquellos fieles a la figura de Sor María. Al igualar a "María de Jesús" con "María la de Jesús Nazareno", se refiere a su propia penitencia ascética. Cuando la mencionan los del pueblo o, como ella dice, "otros menos capaces", es decir, los aldeanos, la nombraban como la hija de su padre y de su madre: María la de Francisco (su alias aquí es Joaquín) y Catalina (su alias es Ana).

Otro pasaje identifica la posible historia de familia de Sor María, por ejemplo:

[...] Llegando a Nazaret bautizó a su beatísima Madre, como queda dicho, y luego con sus discípulos salió a predicar a unos lugares vecinos. En el ínterin, fue la divina Señora a Caná, convidada a la boda que dice el evangelista, porque eran de unos deudos suyos en cuarto grado por la línea de santa Ana.Y estando la gran Reina en Caná tuvieron los novios noticia de la venida del Salvador del mundo [...] (MCD, 838) ${ }^{18}$.

El texto destacado se puede relacionar, en cierta medida, con lo estudiado por Julio Caro Baroja ${ }^{19}$ en relación a los moriscos granadinos. Este autor revela que durante muchas

${ }_{17}$ Nos preguntamos al respecto, si en la primera copia, enviada a Felipe IV, existía o no, el título inicial de la obra y, por lo tanto, si lo que se envió al rey fueron los manuscritos tal como eran, sin el formato de libro trabajado, encuadernado y firmado. De todas formas hemos escogido este pasaje por lo significativo sobre el concepto de imitación, pero hay otro en que claramente se llama a sí misma María de Jesús en honor a Jesús y su madre María, que está 'escondido' también hacia el final del tratado: MCD, 866.

${ }_{18}$ Nótese que la pronunciación de [kaná] se asemeja fonéticamente a [kaná], o la forma en la que los andaluces se refieren a la ciudad de Granada. La palabra ‘deudos' significa tanto ascendientes como descendientes. Por último el término 'ínterin' se utiliza como 'codo temporal' para narrar dos situaciones a la vez: las bodas de Caná de las que se habla en el evangelio, y otras bodas dentro de la línea materna de Sor María que se produjeron en cuarto grado de ascendientes o antepasados.

19 Caro Baroja, J., Los moriscos del reino de Granada, Madrid, Istmo, 1976. 
generaciones y, especialmente, tras la expulsión de la península y de Granada, las familias de "hijosdalgo" con procedencia morisca escondieron sus orígenes, por lo que "si entendemos por origen morisco que en aquellas familias había sangre mora por una de las líneas, esto debe admitirse como muy posible, ya que, según va dicho, muchos de los cristianos viejos del Sur eran hijos de moriscas" ${ }^{20}$. Añade el historiador que, tras el destierro a principios del siglo XVII, los que pudieron quedarse emigraron a otros lugares de la península como las diferentes provincias de Castilla, en donde ya existían moriscos dedicados a la trajinería, actividad común en Ágreda por limitar con Aragón ${ }^{21}$. Por otro lado, no olvidemos que muchos musulmanes de la península fueron obligados a cristianizarse a principios del siglo $\mathrm{XVI}^{22} \mathrm{o}$, como dice la autora, "tuvieron los novios noticias de la venida del Salvador del mundo $[\ldots] "$.

Siguiendo con la denominación de "vil gusanillo", este mote o apodo ${ }^{23}$ tiene una curiosa procedencia popular, tomada de una copla que se cantaba en Semana Santa en Segovia, Burgos, Soria y otros lugares de Castilla. Se entonaba en la festividad del "lavatorio de los pies" 24 y su fragmento más significativo dice:

$$
\begin{aligned}
& {[\ldots] \text { Pues sois un señor tan grande }} \\
& \text { y yo tan vil gusanillo, } \\
& \text { primero prefiero que antes } \\
& \text { sea de fieras comido, } \\
& \text { que consentir que me laves [...] }
\end{aligned}
$$

\section{MENSAJES}

Lo que nos quiere enseñar Sor María de Jesús de Ágreda gracias al concepto de asociación es bastante variado. Estos mensajes son transmitidos a Felipe IV, receptor principal, y

20 Íbid., p. 248.

${ }^{21}$ Cantera Montenegro, E., Espacio, Tiempo y Forma, Serie IV, H. Moderna, t. 7, 1994, pp. 111-114.

${ }^{22}$ Epalza, M., Estructura de acogida de los moriscos emigrantes de España en el Magreb (siglos XIII al XVIII) Alternativas. Cuadernos de Trabajo Social. N. 4 (oct. 1996) pp. 35-58.

${ }^{23}$ Chevalier, M., Quevedo y su tiempo: la agudeza verbal, Barcelona, Crítica, 1992, pp. 39-121. La sociedad culta de la época utilizaba el artificio de 'motejar' dentro de las figuras del equívoco, en el que entraban también juegos de palabras por disociación, juegos con citas bíblicas entre personas y lugares. Se buscaba la brevedad expresiva a través de juegos verbales o verbos lexicalizados e incluso refranes alterados. Vemos con esta referencia que Sor María no escapaba a la tendencia expresiva de su tiempo.

${ }^{24} \mathrm{http}: / / w w w . f u n j d i a z . n e t / f o l k l o r e / 07 f i c h a . p h p ? I D=255$ (27/07/2015): Cuán humilde y amoroso/ tomó una blanca toalla,/ el Señor y puesta al hombro/ una bacía con agua/ para hacer el lavatorio./ Púsose a los pies de Pedro/ el Señor para lavarle,/ y al punto se arrojó al suelo/ diciendo maestro amado/ eso yo no lo consiento./ Eso de lavar los pies/ para mí Señor se queda,/ soy un pobre pescador/ que vengo de baja esfera/ mas vos sois mi Redentor./ Pues sois un señor tan grande/ y yo tan vil gusanillo,/ primero prefiero que antes/ sea de fieras comido,/ que consentir que me laves./ Le miró el Señor y dijo/ si no te dejas lavar,/ no me tendrás por amigo y/ menos podrás gozar/ del eternal paraíso./ Al punto se arrojó al agua/ diciendo lava mis pies,/ y todo mi cuerpo lava/ Señor aquí me tenéis,/ vuestra voluntad se haga./ 
sobre quien la Venerable tuvo influencia espiritual y de estado, así como en su familia. Felipe IV fue gran amante de la Historia, y esta es la razón por la que la autora revela, entre otros temas, las diferencias en el seno de la Iglesia y la separación que supusieron las múltiples formas de entender la doctrina cristiana. También explica la tradición espiritual dentro de la península ibérica desde tiempos lejanos y la espiritualidad inherente en la nación. Por último, dentro de los conceptos que hemos podido identificar, Sor María de Jesús analiza de forma manifiesta todos aquellos intrincados vericuetos de la psicología humana, así como las técnicas que utilizan los santos para poder tener una mayor percepción de Dios y conseguir elevados estados de conciencia.

\section{CONCLUSIÓN}

Mística Ciudad de Dios es una obra que sintetiza el saber de una época, el Siglo de Oro Barroco. Se condensa en ella toda la sapiencia principal que poseía la clase dirigente culta, incluido el clero. Y, por tanto, en este saber han de estar condensadas las llamadas Siete Artes Liberales del Trivium y el Quadrivium ${ }^{25}$.

Por otro lado, Sor María de Jesús de Ágreda, con su aparente limpieza gramatical en la narración de la "divina historia", persigue "el espíritu aristocrático de la Iglesia" donde "la Curia deseaba crear para la propaganda de la fe católica un "arte popular", pero limitando este carácter popular a la sencillez de las ideas y de las formas, tratando de evitar la directa plebeyez de la expresión. Las santas personas representadas deben hablar a los fieles con la mayor eficacia posible, pero en ningún momento descender hasta ellos. Las obras de arte tienen que ganar, conquistar, convencer, pero han de hacerlo con un lenguaje escogido y elevado"26. La originalidad de Sor María de Jesús de Ágreda es configurarlo todo como la "historia" o "divina historia" que narra la "vida de María", sirviéndose para ello de las variables matemáticas ${ }^{27}$ que hemos ido señalando en los apartados anteriores dentro de una estética profundamente barroca, con diversos planos de entendimiento. Es más, creemos que el entender esta obra desde una perspectiva más técnica, podría apoyar trabajos futuros en relación con el pensamiento, la incipiente ciencia, la forma de vida, los

${ }_{25}$ Ferrater Mora, J., Diccionario de Filosofía de bolsillo, Madrid, Alianza editorial, 1987, p. 66: "En la Edad Media se usó el término ars en la expresión artes liberales en un sentido equivalente a 'saber'. Las artes liberales se distinguían de las serviles, que eran las artes manuales. Éstas incluían mucho de lo que se ha llamado 'bellas artes', como la arquitectura y la pintura. [...]".

${ }^{26}$ Hauser, A., Historia social de la literatura y del arte, (T. II), Barcelona, Labor punto omega, 1985, p. 105.

${ }^{27}$ Hauser, A., Historia social de la literatura y del arte, (T. I), Barcelona, Labor punto omega, 1985, p. 402: "La concepción científica del arte, que constituye los fundamentos de la enseñanza académica, comienza con León Battista Alberti. Él es el primero en expresar la idea de que las matemáticas son el cuerpo común del arte y de la ciencia, ya que tanto la doctrina de las proporciones como la teoría de la perspectiva son disciplinas matemáticas. [...] Pero si el técnico y el investigador de la naturaleza, por razón de sus conocimientos matemáticos, tiene la pretensión de ser un intelectual, también el artista, que tantas veces se identifica con el técnico y el investigador de la naturaleza, quiere ser distinguido del artesano y cuenta el medio que le sirve de expresión entre las artes liberales". 
giros expresivos de aquellas gentes, en especial el de la clase culta, destinataria o receptora del mensaje $\mathrm{e}^{28}$.

Los ejemplos en relación con las artes liberales, que aparecen en Mística Ciudad de Dios se podrían resumir a modo de conclusión de la siguiente forma:

Con la Gramática se busca la limpieza en el concepto de la palabra sagrada, escogiendo para ello los pasajes bíblicos que en todo el tratado suman $3199^{29}$. A su vez, la prudencia, que es el "pilar" sobre el que se construye toda la obra, hace de la Retórica el instrumento para que lo dicho no sea estridente, aunque se hable de conceptos muy delicados y "políticamente incorrectos". La Dialéctica, que es la capacidad de síntesis en una sola "divisa" de las más diversas interpretaciones filosóficas, recurre a la asociación o analogía de términos, dando lugar a una riqueza extraordinaria de líneas argumentales dispuestas de forma contrapuntística. La Música, con su fundamento matemático y armónico ${ }^{30}$, la Aritmética ${ }^{31}$, basada en el número, la Geometría ${ }^{32}$ y la Astrología ${ }^{33}$ de los cuerpos perfectos como lo es el de la Jerusalén Celeste, todo ello teje la estructura de Mística Ciudad de Dios, que puede considerarse un manual mariológico de Teología.

Gráficamente vemos interpretadas todas estas artes en la Biblioteca del Real Monasterio de San Lorenzo del Escorial. Los frescos pintados en la bóveda del recinto nos explican descriptivamente las diferentes escuelas de pensamiento o sectas clásicas y cristianas que conforman la Filosofía. Avanzamos bajo la Gramática, la Retórica, la Dialéctica, Aritmética,

${ }_{28}$ Íbid., (T. I), pp. 281-282: "El gusto por el arte difícil y complicado se explica, la mayoría de las veces, por una intención más o menos manifiesta de distinción social: el atractivo estético del sentido oculto, de las asociaciones forzadas, de la composición inconexa y rapsódica de los símbolos inmediatamente evidentes y que nunca se agotan completamente, de la música difícilmente recordable, de la "melodía que al principio no se sabe cómo ha de terminar", en una palabra, de toda la fascinación de los placeres y los paraísos secretos".

${ }_{29}$ Martínez Móñux, A. María, mística ciudad de Dios. Una mariología interactiva, Burgos, Monte Carmelo, 2001, p. 37.

${ }^{30}$ Sor María de Jesús de Ágreda, Mística Ciudad de Dios, [1965], Madrid, Solaguren, C. (ed.), 2009. "El orden de tus potencias y sentidos ha de ser una armonía de instrumentos de música suavísima y delicada[...]”(p. 519). "[...] le era tan fácil de usar de ella como lo es para un músico tocar un instrumento de su arte en que es muy sabio; [...]” (p. 359). "[...] y todo esto junto y gobernado por la sabiduría de una doncella hacía armonía admirable y dulcísima para los oídos del Señor y admirable para todos los espíritus angélicos." (p. 418).

31 Íbid., p. 188: “[...] sembrada de letras o cifras de finísimo oro [...]”, de esta forma explica Sor María de Jesús de Ágreda que el concepto de "María" se puede entender a través de la Aritmética o la Gramática, superponiendo ambas disciplinas.

32 Borrás Gualis, G. M., Esteban Lorente, J. F., Álvaro Zamora, M. I., Introducción general al arte, Madrid, Istmo, 1985, p. 463: "El concepto de geometría sagrada posee raíces musulmanas porque "no pudiendo representar a Dios en forma humana como hace el Cristianismo, busca plasmarlo a través de su Creación. Para ello se fundamenta en la Ciencia: en la matemática, la geometría y el número, formas perfectas de representación del Universo (Pitágoras, Aristóteles y Platón). Por eso la decoración geométrica es, a la vez, Ciencia y Arte, y no le importa al musulmán someterse a unas normas geométricas con tal de lograr la belleza objetiva e impersonal basada en un principio ordenador: el número o lo armoniosamente interrelacionado".

33 Sor María de Jesús de Ágreda, Mística Ciudad de Dios, [1965], Madrid, Solaguren, C. (ed.), 2009, p. 363: "Conoció el número de las estrellas y todos los influjos que le comunicaban a la tierra, a sus vivientes y no vivientes, los efectos que en ellos causaban, cómo los alterna y mueven”. 
Música, Geometría o Astrología, hasta llegar a la Teología, la reina del Conocimiento o el vademécum de la Sabiduría ${ }^{34}$.

Para finalizar, a modo de resumen, afirmamos que lo que hasta ahora se consideraba una "extraña" obra piadosa y moralizante es en realidad una síntesis del saber. Esta "divina historia" encriptada por prudencia política y eclesiástica puede ser estudiada y planteada desde otras líneas de investigación con una perspectiva más "terrenal".

\section{BIBLIOTECA DEL REAL MONASTERIO}

DE SAN LORENZO DEL ESCORIAL

Esquema de la representación pictórica de las diferentes ciencias en la cúpula de la Biblioteca

\section{TEOLOGÍA}

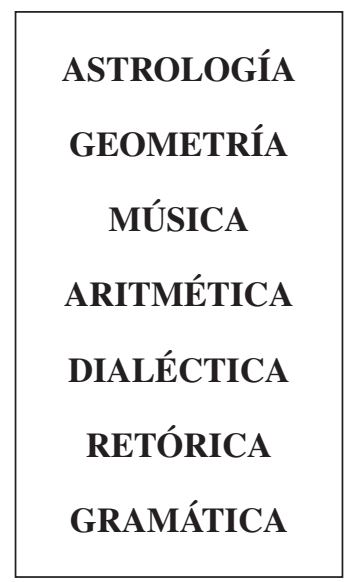

FILOSOFÍA

${ }^{34}$ http://josecarlosfernandezromero.com/2013/02/04/la-biblioteca-de-el-escorial-un-tratado-hermetico/ (18/10/2015). Hernández, J. C. La biblioteca de El Escorial, un tratado hermético: "la Teología nace, como disciplina, en la Escuela Catequética de Alejandría [...] fundada por [...] Clemente y Orígenes: conocedores ambos de las doctrinas herméticas y cabalísticas, las únicas que permiten la recta interpretación de las alegorías contenidas en los libros del Antiguo y Nuevo Testamento". 